\title{
Applying remote sensing techniques to monitor green areas in Tashkent Uzbekistan
}

\author{
Ilhomjon Aslanov ${ }^{1, *}$, Uzbekkhon Mukhtorov ${ }^{1}$, Rahimjon Mahsudov ${ }^{1}$, Umida \\ Makhmudova $^{1}$, Saida Alimova ${ }^{2}$, Lobar Djurayeva ${ }^{3}$, and Oyatillo Ibragimov ${ }^{4}$ \\ ${ }^{1}$ Tashkent Institute of Irrigation and Agricultural Mechanization Engineers, Tashkent, Uzbekistan \\ ${ }^{2}$ National University of Uzbekistan, Tashkent, Uzbekistan \\ ${ }^{3}$ Chirchik State Pedagogical Institute, Chirchik, Uzbekistan \\ ${ }^{4}$ Tashkent Institute of Irrigation and Agricultural Mechanization Engineers, Tashkent, Uzbekistan
}

\begin{abstract}
Land use and land cover (LULC) change are one of the most important signals of regional environmental monitoring and study. Recently, the pull of capital cities has snowballed, an increasing number of people moving to the cities, especially in developing countries. Consequently, as more people arrive at cities, the more pressure will be on land. Land price getting high and constructions try using open green areas. A wide variety of green areas of different sizes will be solve many urban diseases and ecological problems at the same time improve the quality and life of urban residents, as urban green area provides various ecosystem services. The green area includes parks, woodlands, nature reserves and bare lands. With the population increase and expansion of cities, an increasing amount of open area, woodland and bare land has been converted into construction land, buildings due to the increasing demands and residential land. For the accuracy assessment, we applied an automatically supervised classification using the software QGIS 3.18. The reference values were based on ground truth data and visual interpretation.
\end{abstract}

\section{Introduction}

Green land areas are critical natural as a resource in big cities [1, 5]. Nowadays, the increase in population and human activities is increasing the demand on urban areas. LULC study is essential for determining the current scenario and for managing natural resources and environmental problems $[2,16]$. In the last 30 years after independent Republic of Uzbekistan Tashkent become the political, social and economic capital, rapidly developing trend of urbanization has made significant changes of land use and land cover of the city. Frequently updated surface maps critical Geographic information systems (GIS) techniques are one of the most commonly used tools for land use classification in urban areas $[2,6]$. It is not only fast and automatic tools at the same time free from statistical assumption and manipulation of statistic numbers [3, 10-14]. For the analysing LULC changing used

\footnotetext{
*Corresponding author: ilhomaslanov@,tiiame.uz, $\underline{\text { ilhomaslanov@gmail.com }}$
} 
methods of Normalize Different Vegetation Index (NDVI) and Normalize Different Buildup Index (NDBI) algorithm to separate green and bare land areas and residential, infrastructure areas by using Landsat images. One of the automatic mapping tools based on the arithmetic calculation of using Landsat images: Red(R), Near Infrared (NIR) [4]. To improve and modified of LULC classification was used NDBI algorithms on the arithmetic calculation using Landsat images three bands: Red(R), Near Infrared (NIR) and Medium Infrared (MIR) by using the concept of original NDBI approach and proposed a revised version of NDBI algorithm [4, 7, 9].

During the analysis, there are still problems related to the classification result, particularly the mixing of built-up land and infrastructures with others results classification. Using Landsat images for multispectral classification approach is developed through the method for combining NDVI and NDBI the same pixel value for each land cover/land change class [8-11]. In last decade NDBI is widely used for extracting urban built-up areas. Monitoring the green index changing and build up an area change requires an adequate understanding of landscape features, the selection of suitable data and appropriate change detection method adopted in relation to the aims of the research. Moreover, remote sensing methods and Landsat data used for specific conditions in terms of temporal, spatial, spectral and radiometric characteristics on this research we try analysing automatic and quicker spectral signature analysis tools, with which we want to create a monitoring new built-up and infrastructure index $[13,15]$.

Urban LULC monitoring mapping using remote sensing imagery is an emerging branch, the interest of Tashkent city in the last three decades city becomes the new big construction area that why studying, mapping, and managing green spaces is of city critical [17-20]. Landsat data from 1990 to 2019 permits several possibilities in terms of green and bare land areas [19].

\section{Study area}

Tashkent is the main trading and economic centre and is developing rapidly in last decades located between $69^{\circ} 10^{\prime} 6^{\prime \prime}$ to $69^{\circ} 21^{\prime} 34.74^{\prime \prime}$ east longitudes and $41^{\circ} 23^{\prime} 41^{\prime \prime}$ north to $41^{\circ} 13^{\prime} 31^{\prime \prime}$ north latitudes (Fig. 1). Tashkent city is located limited area (334.8 ha) land use/land cover and completely bordered. The city has a humid subtropical climate; however, the elevation keeps temperatures moderate. The altitude varies from 455 meters. Temperatures on summer average between $32^{\circ} \mathrm{C}$ and $37^{\circ} \mathrm{C}$; in winter around $-1^{\circ} \mathrm{C}$ to $25^{\circ} \mathrm{C}$. The remote sensing and geographic information system technique makes it possible to study and monitoring changes in $\operatorname{LULC}[17,21]$. 


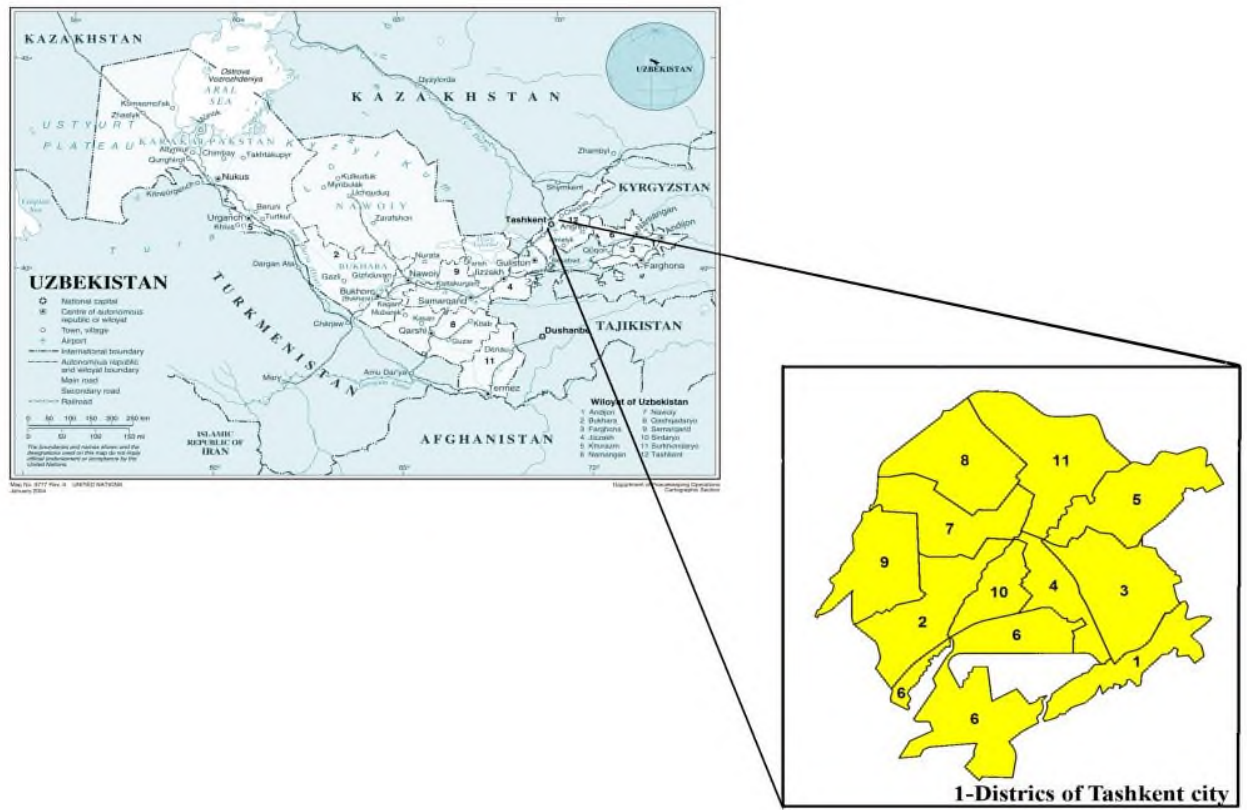

Fig. 1. Location of Tashkent city.

\section{Methods}

Geo-information systems (GIS) tools and techniques are important to instantly assess the study and monitoring dynamics of LULC changes at a wider multispectral resolution, rather than spending more time on the in-situ research. GIS techniques have a large potential to monitor and evaluate processes urban areas. Assess and monitor the LULC in urban areas with GIS and RS techniques the LULC analysis plays an important and key role as one of the major sources of state-of-the-art and physically-based information, whereas GIS provides the toolbox that improves the ability of data integration, data analysis and data extraction from the source (Landsat images) [21-28].

To understand the LULC changes as a result of land-cover classification. The amounts of LULC changes can be assessed by using remote sensing indices like Normalize Different Vegetation Index (NDVI) and Normalize Different Build-up Index (NDBI). With the help of these indices it becomes possible to establish a basis classification of LULC changes. NDVI and NDBI, calculated using satellite images, have revealed the capability of GIS for systematic, reliable and spatially extensive monitoring of green and build-up indexes. According to studies [25, 31-34], they have also shown that with the help of the integrate maps use to urban planning maps.

\section{Data}

For the analysing used images Landsat-5 TM and Landsat 8 (OLI \& TIRS) data of summer seasons from 1990 to 2019 (path 142, row 41; cloud cover less than 1\%) were acquired for built-up and structure areas extraction for the study. The Landsat images has eight reflectance bands with a resolution of $30 \mathrm{~m}$, one panchromatic band with $15 \mathrm{~m}$ and two thermal bands with a resolution of $100 \mathrm{~m}$. The specifications of Landsat- 5 TM and Landsat 8 (OLI \& TIRS) are shown in Table 1. The raw data were analysed using QGIS 3.18 software 
without atmospheric correction. In the current study; the images were geometrically referenced to the WGS-84 coordination system [22, 29].

Table 1. Landsat spectral bands (Source: www.usgs.gov).

\begin{tabular}{|c|cc|cc|c|}
\hline \multicolumn{3}{|c|}{ Landsat-5 TM Bands $(\boldsymbol{\mu m})$} & \multicolumn{3}{|c|}{ Landsat-8 OLI and TIRS Bands $(\boldsymbol{\mu m})$} \\
\hline & & & $30 \mathrm{~m}$ Coastal/Aerosol & $0.435-0.451$ & Band 1 \\
Band1 & $30 \mathrm{~m}$ Blue & $0.45-0.52$ & $30 \mathrm{~m}$ Blue & $0.452-0.512$ & Band2 \\
Band2 & $30 \mathrm{~m}$ Green & $0.52-0.60$ & $30 \mathrm{~m}$ Green & $0.533-0.590$ & Band3 \\
Band3 & $30 \mathrm{~m}$ Red & $0.63-0.69$ & $30 \mathrm{~m}$ Red & $0.636-0.673$ & Band4 \\
Band4 & $30 \mathrm{mNIR}$ & $0.77-0.90$ & $30 \mathrm{mNIR}$ & $0.851-0.879$ & Band5 \\
Band5 & $30 \mathrm{~m}$ SWIR-1 & $1.55-1.75$ & $30 \mathrm{~m}$ SWIR-1 & $1.566-1.651$ & Band6 \\
Band6 & $60 \mathrm{~m}$ TIR & $10.40-12.50$ & $100 \mathrm{~m}$ TIR-1 & $10.60-11.19$ & Band 10 \\
& & & $100 \mathrm{~m}$ TIR-2 & $11.50-12.51$ & Band 11 \\
Band 7 & $30 \mathrm{~m}$ SWIR-2 & $2.09-2.35$ & $30 \mathrm{~m}$ SWIR-2 & $2.107-2.294$ & Band 7 \\
Band 8 & $15 \mathrm{~m}$ Pan & & $15 \mathrm{~m}$ Pan & $0.503-0.676$ & Band 8 \\
& & & $30 \mathrm{~m}$ Cirrus & $1.363-1.384$ & Band9 \\
\hline
\end{tabular}

\subsection{Image acquisition and pre-processing}

For the image processing proposed in Landsat-5 TM and Landsat 8 (OLI \& TIRS) images from 1990 to 2019 specifically summer season which vegetation index will be maximum. Indexes on rea research based on 4 bands of satellite images Red, NIR, SWIR, and TIRS1. The analysis of LULC in the Tashkent city required several steps to interpret the results (Fig 2). Normalized Difference Vegetation Index (NDVI) was applied to detect the canopy cover from the satellite images. The NDVI ranges from -1 to 1 and assesses whether the target being analysed contains photosynthesis active vegetation or not by using Equation 1 $[1,5,30]$ :

$$
\mathrm{NDVI}=(\mathrm{NIR}-\mathrm{RED}) /(\mathrm{NIR}+\mathrm{RED}),
$$

where: NIR is the Near InfraRed band of Landsat sensor (band 4 for Landsat TM 5 and Landsat-5 TM; band 5 for Landsat 8 OLI); and RED is the red band of Landsat sensor (band 3 for Landsat TM 5 and Landsat ETM+ 7; band 4 for Landsat 8 OLI).

Once the NDVI was calculated, vegetation cover above 0.3 NDVI was removed from each satellite image in order to improve the accuracy of the Soil-Adjusted Vegetation Index (SAVI) values ranging from -1.5 to 1.5. The SAVI enables the sufficient description of the soil-vegetation system and soil type classification which is essential for estimating the consequences of land-cover change by using Equation $2[1,5]$.

$$
\mathrm{NDBI}=(\mathrm{SWIR}-\mathrm{NIR}) /(\mathrm{SWIR}+\mathrm{NIR}) \text {. }
$$

After all, the NDVI and NDBI- analysis's based maps were stacked to create final landcover land changing maps. When a potential remote sensing index for LULC changing was found to describe the green index, the footprint (to verify whether build-up or vegetation cover is dominantly occupying the Tashkent city) of green index in the Tashkent city was evaluated for all years (1990-2019). 


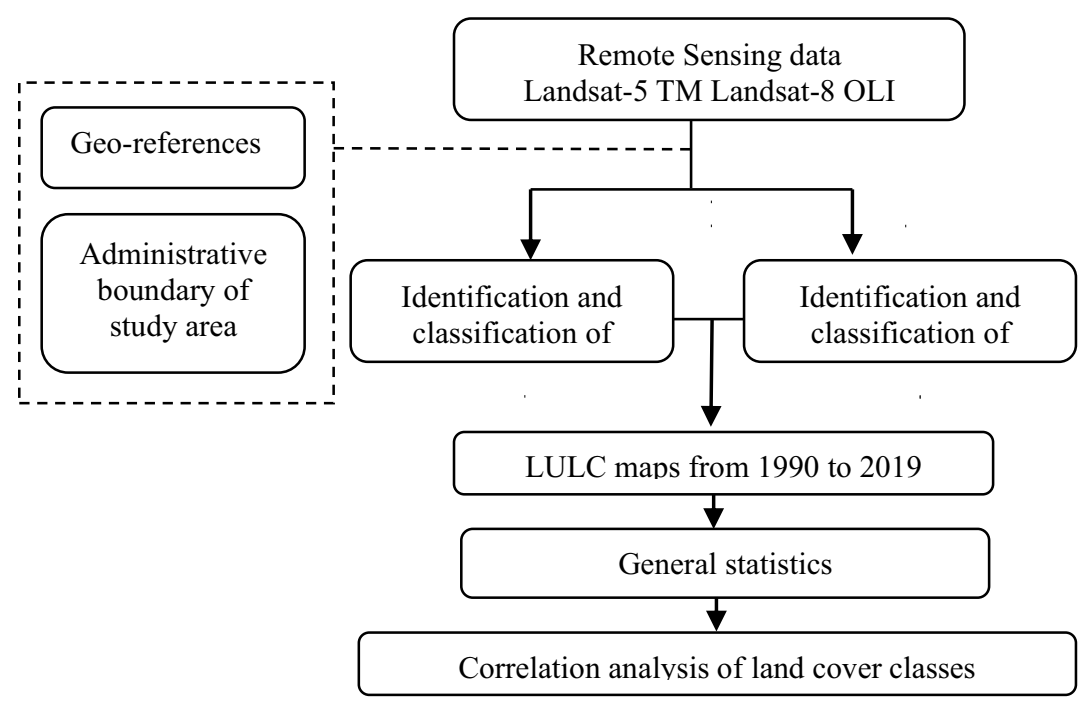

Fig. 2. Flow chart for adopted methodology.

General correlation analysis was performed using $\mathrm{R}$ software to identify how the vegetation and bare land correlated with other classifications. Landsat images segmentation was performed in three steps in order to obtain optimized image segments. In the research created a three class level. Finally, normalized spectral difference segmentation was used for the classification level.

\section{Results}

Results of study land use/land cover index for transforming remote sensing data was proposed and evaluated for mapping metropolitan (built-up) area and vegetation (bare land) areas. The index was able to study of changing built-up and vegetation areas with a single calculation and was referred to as the Built-up and Vegetation classes. The classification indices could not perfectly differentiate between vegetation and bare land because both of these land types show similar spectral responses in all Landsat $5 \mathrm{TM}+$ bands, Landsat 8 OLI that's why during the classification we did joint class for vegetation and bare land. For Build-up and infrastructures (roads) of the city we did joint class as metropolitan.

Results of maps were created for all years; the dynamics of the LULC changing to the study area were showing whether the actual area of changing the lake was preoccupied by Metropolitan Urban and Vegetation (bare land). As far as the actuality was identified, the above-mentioned step-by-step methods were enough to tell the average annual Urban and Vegetation (bare land) rate of the Tashkent city. The analysing Landsat satellite observations based LULC changing mapping exhibits that significant changes in metropolitan area followed by constructions of new building and infrastructures. The study indicates that the total agricultural area was more than 12000 ha, covering $38.46 \%$ of land in 1990 , which decreased significantly to less than 2661 ha $(6.32 \%)$ in 2019 . In marked contrast to the trend noticed with, built-up lands and vegetation (bare land) witnessed rapid changes over the period. 


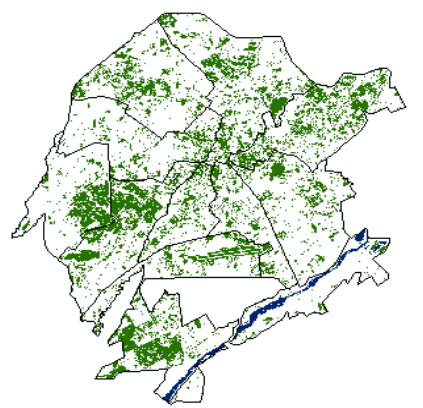

1990

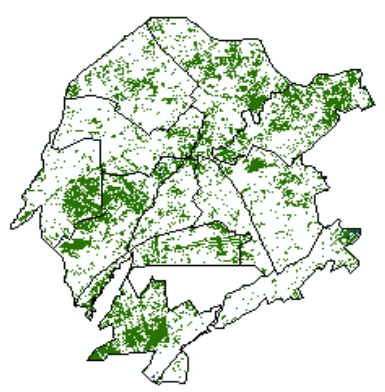

1994
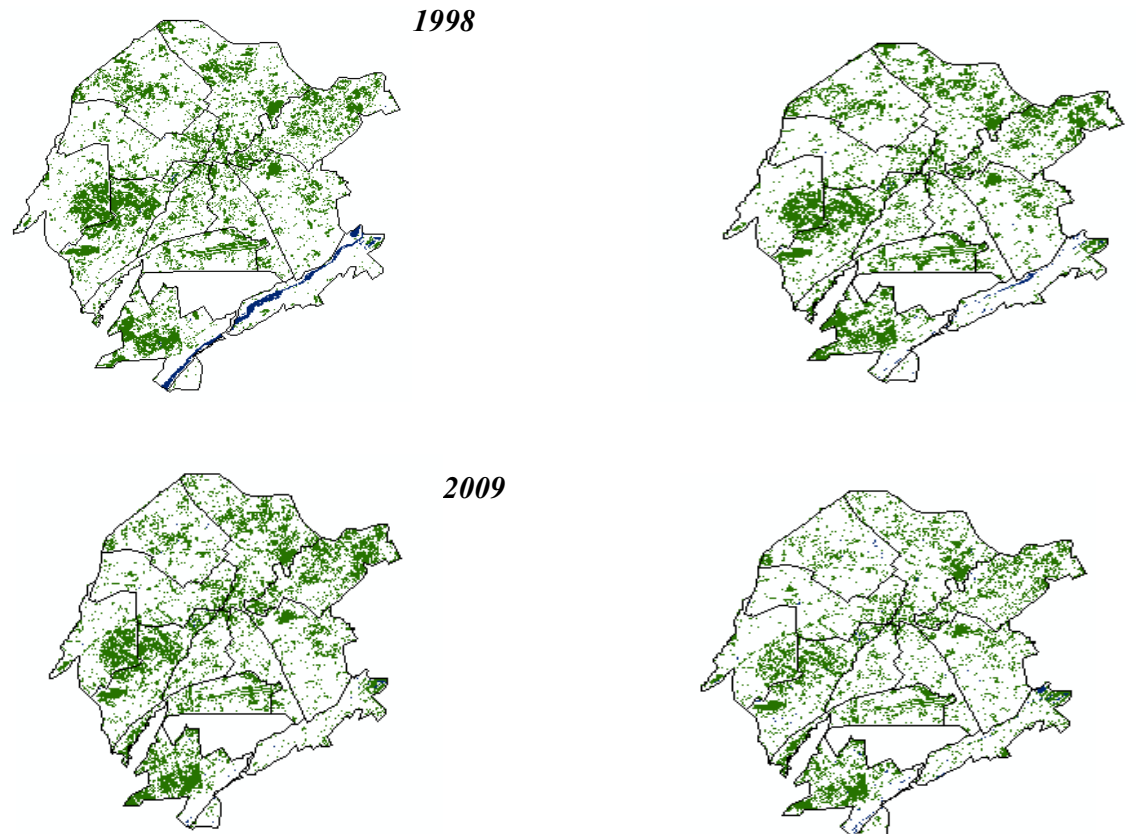

2009

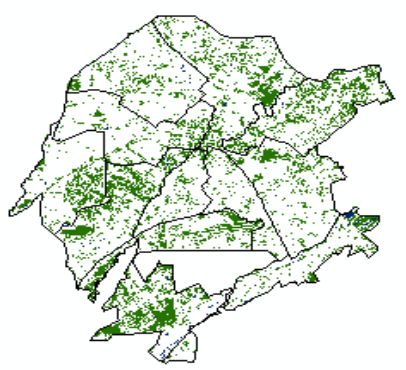

2011

2015

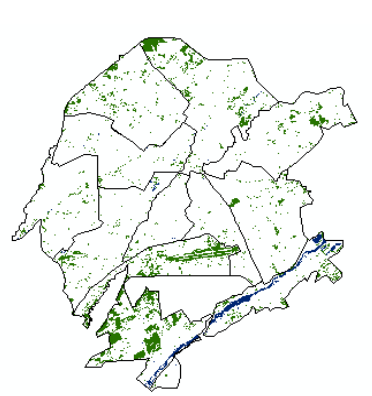

2019

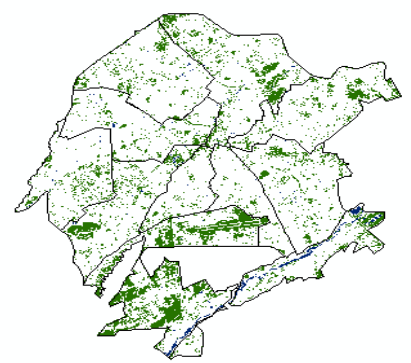

Fig. 3. Identification and classification of LULC from 1990 to 2019. 


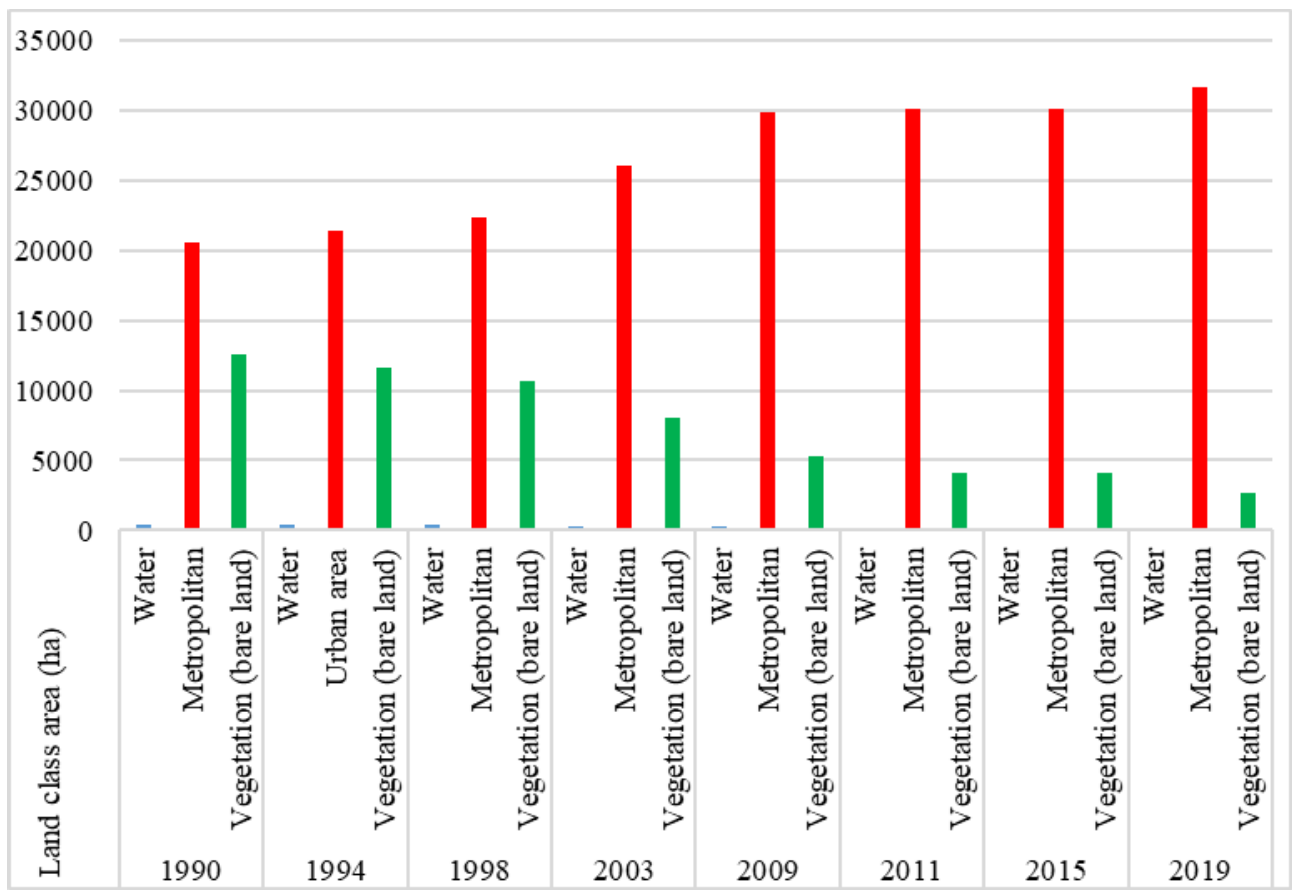

Fig. 4. Changing of land use/land cover classes from 1990 to 2019.

The metropolitan growth was analysed with respect to its coverage in the city during 1990, and 2019 (Fig.4). The metropolitan land increased rapidly with 59.23\% growth during 1990-2019. The study exhibits the metropolitan area increased from 20,497.95 ha to 31,596.48 during 1990-2019 inside the municipal limit, with $21.22 \%$ growth and later, increased to $12,543.39$ ha to $2,661.81$ ha in 1998 with $24.41 \%$ growth. The built-up growth rate was $0.33 \% /$ year and $1.51 \mathrm{~km}^{2} /$ year during 1990-2019 respectively. The contrasting increase in metropolitan area rates in later periods (1998-2011) clearly reflects the intense pressure exerted by this category of land use over categories.

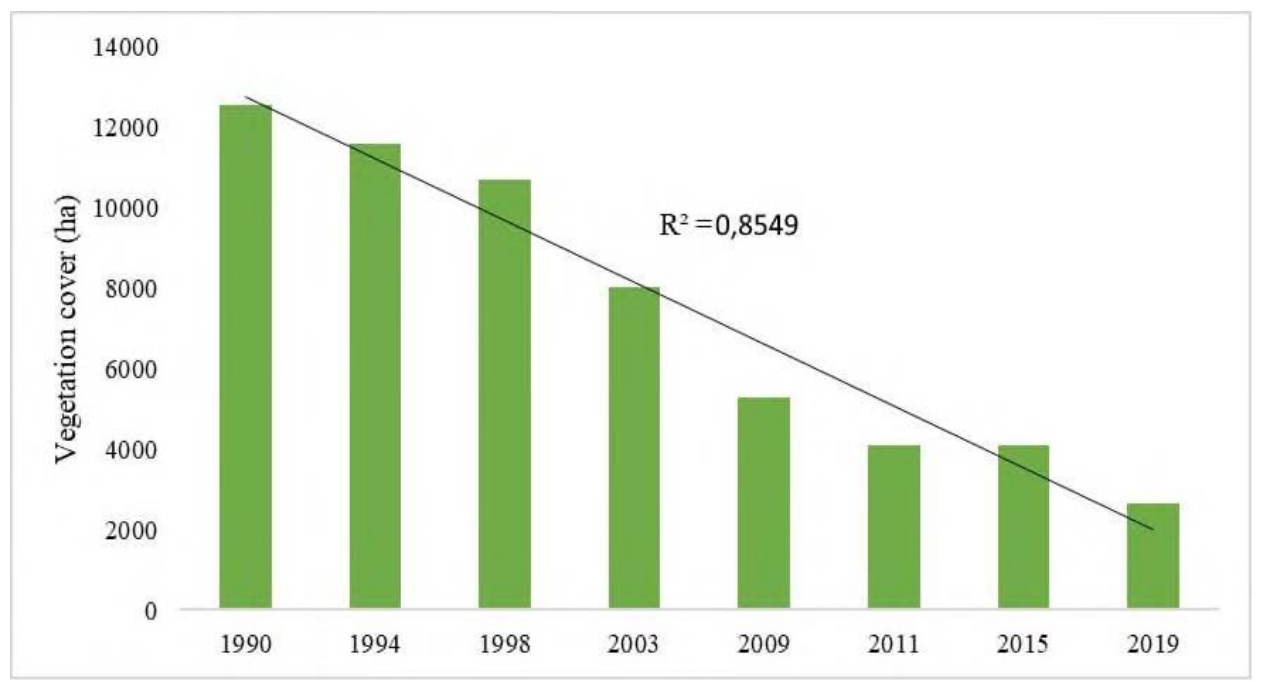

Fig. 5. Significance analysis of green cover of Tashkent. 
As can be seen in Fig. 5, there were evidentially upward trends for the decreasing of the vegetation and bare land areas, despite experiencing fluctuations. Vegetation (bare lands) areas decrease approximately 9,000 ha in 30 years, whereas metropolitan areas accounted for increase to 9000 ha. Both land use cover/land cover classes have invaded another roughly 2,661.81 ha of the Tashkent city, respectively, by the end of 2019. After having calculated the rate changing LULC, a simple correlation analysis was carried out for landcover classes to understand how the changes in each class interconnected each other (Fig 5). The data derived from this diagram can be used for further assessment; hence, accuracy reflects the reliability of data. The pivot table with kappa statistic is represented. The overall accuracy of thematic map is $85 \%$ and the kappa statistic was 0.85 . Decreasing of vegetation (bare land) area will negative affect of sustainable developing of the city near future.

\section{Conclusions}

Study have developed two new automatic and quicker spectral signature analysis tools to separate metropolitan (urban built-up) area from vegetation (bare land) area of Tashkent city. The analysis gives a superior outcome in terms of accuracy as compared LULC classes. Research work also concludes that remote sensing data can be used efficiently in LULC index modelling techniques in order to study the urban areas and conurbation of any growing cities. To provide better information about land use/land cover pattern and behaviour, this technique needs high level of interpretation and spectral identification classes. Digital image processing and creating map techniques can bring huge achievement to monitoring cities. This is research has been demonstrated how a spatially disaggregated 'green index' could be identified as a main factor.

\section{References}

1. I. Aslanov, S. Khasanov, Y. Khudaybergenov, M. Groll, Ch. Opp, F. Li, E. R. DelValle, E3S Web Conf., 227, 02005 (2021)

2. I. Cârlan, D. Haase, A. Große-Stoltenberg, and I. Sandric, Urban Ecosyst., 23, 363-377 (2020)

3. G. Kuc and J. Chormański, Remote Sens. Spat. Inf. Sci. - ISPRS Arch., 42 43-47 (2019)

4. H. Nouri, Sustain, 10, 1-14 (2018)

5. J. Xue, and B. Su, J. Sensors, 2017,17 (2017)

6. P. Addabbo, M. Focareta, S. Marcuccio, C. Votto, and S. L. Ullo, Acta IMEKO, 5, 4454 (2016)

7. D. Frantz, Remote Sens. Environ., 252, 2-9 (2020)

8. A. Lefebvre, C. Sannier, and T. Corpetti, Remote Sens., 8, 112128 (2016)

9. M. Kopecká, D. Szatmári, and K. Rosina, Remote Sens. Environ., 6, 2-9 (2017)

10. S. Dimitrov, G. Georgiev, M. Georgieva, M. Gluschkova, V. Chepisheva, P. Mirchev, M. Zhiyanski, One Ecosyst., 3, e21610 (2018)

11. M. M. Maroneze, L. Q. Zepka, J. G. Vieira, M. I. Queiroz, and E. Jacob-Lopes, Rev. Ambient. e Agua, 9, 445-458 (2014)

12. K. Rosina and M. Kopecká, 6th Int. Conf., Cartogr. GIS, 308 (2016)

13. S. Lang, E. Schöpfer, D. Hölbling, T. Blaschke, M. Moeller, T. Jekel, E. Kloyber, Use 
Landsc. Sci. Assess. Environ. Secur., 93-105 (2007)

14. M. Majidi Nezhad, A. Heydari, L. Fusilli, and G. Laneve, World Congr. Civil, Struct. Environ. Eng., 2-9 (2019)

15. A. A. Kozlova, A. V. Khyzhniak, I. A. Piestova, and A. A. Andreiev, 17th Int. Conf. Geoinformatics, Theor. Appl. Asp., 14-19 (2018)

16. A. L. Uren, C. Laukamp, A. D. George, S. A. Occhipinti, and A. R. A. Aitken, Remote Sens. Environ., 252, 1-8 (2020)

17. S. M. Labib and A. Harris, Eur. J. Remote Sens., 51, 231-240 (2018)

18. S. Gadal, W. Ouerghemmi, R. Barlatier, and G. Mozgeris, GISTAM 2019 - Proc. 5th Int. Conf. Geogr. Inf. Syst. Theory, Appl. Manag., 97-104 (2019)

19. E. Schöpfer Lang, S., Blaschke, T., Int. Arch. Photogramm. Remote Sens. Spat. Inf. Sci., XXXVII-5/W1, Tempe, AZ, 1-6, 97-104 (2005)

20. J. Deng, Y. Huang, B. Chen, Ch. Tong, P. Liu, H. Wang, Y. Hong, Remote Sens., 11, 1230 (2019)

21. S. Lahoti, M. Kefi, A. Lahoti, and O. Saito, Sustainability, 11, 23125 (2019)

22. T. T. Van, N. D. H. Tran, H. D. X. Bao, D. T. T. Phuong, P. K. Hoa, and T. T. N. Han, Proceedings, 2, 12-23 (2017)

23. O. Ruzikulova, N. Sabitova, and G. Kholdorova, E3S Web Conf., 227, 03004 (2021)

24. K. Khakimova, I. Musaev, and A. Khamraliev, E3S Web Conf., 227, 02003 (2021)

25. N. Teshaev, B. Mamadaliyev, A. Ibragimov, S. Khasanov, InterCarto. InterGIS, 26(3), 324-333 (2020)

26. Y. Peng, F. Li, N. Xu, R. Kulmatov, K. Gao, G. Wang, Y. Zhang, Y. Qiao, Y. Li, H. Yang, S. Hao, Q. Li, S. Khasanov, Chinese Journal of Eco-Agriculture, 29(2), 312-324 (2021)

27. R. Kulmatov, A. Taylakov, S. Khasanov, Environ. Sci. Pollut. Res., 28(10), 1224512255 (2021)

28. R. A. Kulmatov, S. A. Adilov, S. Khasanov, IOP Conf. Ser.: Earth Environ. Sci., 614(1), 012149 (2020)

29. K. T. Deribew and D. W. Dalacho, Environ. Syst. Res., 8, 23-32 (2019)

30. M. Batty, M. Dodge, B. Jiang, and A. Smith, Environ. Syst. Res., 8, 26154 (1998)

31. M. Vittek, A. Brink, F. Donnay, D. Simonetti, and B. Desclée, Remote Sens., 6, 26981(2014)

32. M. Pedersen Zari, Int. J. Sustain. Built Environ., 4, 1248 (2014)

33. T. Fung, Geocarto Int., 7, 569-579 (1992)

34. X. Xu, X. Shi, S. Zhang, G. Ding, Q. Miao, L. Zhou, Chinese Sci. Bull., 51, 23648 (2006) 